\title{
Effect of Thiamine Repletion on Cardiac Fibrosis and Protein O-Glycosylation in Diabetic Cardiomyopathy
}

\author{
Yuka Kohda*, Takao Tanaka and Hitoshi Matsumura
}

Laboratory of Pharmacotherapy, Osaka University of Pharmaceutical Sciences, Nasahara, Takatsuki, Osaka, Japan

\begin{abstract}
Once diagnosed with diabetes mellitus, the risk of diseases, such as nephropathy, neuropathy, retinopathy and heart disease also increases. The complication of diabetes accompanying myocardial disorder is known as diabetic cardiomyopathy, which is characterized by ventricular dilation that is usually asymptomatic as diabetes progresses. Myocardial fibrosis is closely related to diastolic dysfunction. Thiamine (vitamin $\mathrm{B}_{1}$ ), an essential micronutrient, has been reported to attenuate diabetic complications and all diabetics may be lacking in thiamine. Thiamine is a coenzyme utilized at multiple steps of glucose metabolism. We believe that thiamine repletion under hyperglycemia might activate glucose oxidation and reduce the overflow of glucose to the hexosamine biosynthesis pathway of glucose metabolism with concomitant reduction of diabetic lesions. The aim of this article is to highlight the role of thiamine, an important factor that combats diabetic complications, especially diabetic cardiomyopathy and also elucidate its impact on O-glycosylated protein in diabetes. Finally, we discuss the ability of thiamine repletion to prevent metabolic syndrome and obesity, which are considered prediabetic states, as well as prediabetic cardiomyopathy.
\end{abstract}

Keywords: Cardiac fibrosis; Diabetic cardiomyopathy; Thiamine repletion; Protein $\mathrm{O}$-glycosylation; Pyruvate dehydrogenase; Metabolic syndrome

\section{Introduction}

Diabetes mellitus, a well recognized risk factor for the development of heart failure, was initially linked to heart disease 30 years ago with the Framingham Heart Study [1-7]. Cardiac failure in diabetes is primarily due to ischemic heart disease caused by coronary artery disease. However, it is proposed that the incidence of heart failure in diabetes, except for atherosclerotic coronary lesions, is $4-5$ times higher compared to nondiabetics. Rubler et al. propounded the concept that diabetic cardiac failure without coronary lesions is classified as diabetic cardiomyopathy and it is caused by systolic and diastolic dysfunction due to diabetes itself [8]. Conversely, patients with heart failure are also at a higher risk of developing diabetes [9]. It has been revealed that there is a significant overlap in the development of both diabetes and cardiac failure. Diabetes is characterized by increased metabolism of free fatty acids due to reduced glucose utilization. The mutation of thiamine (vitamin $\mathrm{B}_{1}$ ) transporter gene SLC19A2 is linked to type 2 diabetes mellitus [10-12]. We believe that thiamine has the ability to increase carbohydrate metabolism and the amount of catalytic thiamine absorbed must necessarily increase if glucose is to be metabolized in large quantities.

\section{Thiamine Status in Clinical Diabetes}

Thiamine is a coenzyme that is involved in multiple steps of glucose metabolism and interacts with transketolase (TK) and pyruvate dehydrogenase $(\mathrm{PDH})$ during decarboxylation [13]. It has been reported that thiamine is deficient in the blood of diabetic patients [14]. Thornalley et al. discussed that low plasma thiamine concentration in diabetes may be of limited significance if tissues can upregulate the gene expression and protein levels of thiamine transporters and maintain normal TK activity [15]. The above phenomenon occurs in the normoglycemic state $[16,17]$. However, Babaei-Jadidi et al. suggested that their findings in experimental diabetic models indicate that the phenomenon does not occur in renal glomeruli in the diabetic state in which the enhanced hexosamine biosynthetic pathway may block increased expression of the genes that encode thiamine transporter-1, thiamine transporter- 2 and reduced folate carrier- 1 and their proteins [18]. Previous studies have suggested that TK activity and level of TK protein decreases in renal glomeruli in diabetes [18]. Similar impairment of thiamine uptake and metabolism may occur in the retina and peripheral nerve in diabetes $[19,20]$. Therefore, reduced folate carrier-1 is associated with impaired gene expression and decreased protein levels in the retina of diabetic patients [20]

Thiamine deficiency in diabetes is caused by the excretion of thiamine in urine with osmotic diuresis, but the metabolic consumption may be due to increased glucose metabolism in hyperglycemia $[21,22]$. Renal clearance of thiamine has been reported to increase in diabetic patients. A link between low plasma thiamine concentration and a profound increase in renal clearance and fractional excretion of thiamine has also been suggested [15]. Thornalley et al. suggested that mechanisms of increased renal clearance of thiamine in diabetes probably involve decreased reuptake of thiamine in renal proximal tubules $[15,18,23]$. Thiamine clearance was dysfunctional in diabetic patients who had normal glomerular filtration rates that were assessed by creatinine clearance. Renal mishandling of thiamine in diabetic patients has been suggested to be an early marker of renal dysfunction in diabetes and, linked to the locus of renal thiamine reuptake, is indicative of proximal tubule dysfunction [15].

\section{Diabetic complications and thiamine repletion}

The pathogenesis of diabetic complications is caused by continuing hyperglycemia that cannot be handled by the glucose oxidation

Corresponding author: Yuka Kohda, Laboratory of Pharmacotherapy, Osaka University of Pharmaceutical Sciences 4-20-1 Nasahara, Takatsuki, Osaka 569-1094 Japan, Tel: +81-72-690-1047; Fax: +81-72-690-1047; E-mail: ykohda@gly.oups.ac.jp Received November 24, 2011; Accepted February 11, 2012; Published February 16,2012

Citation: Kohda Y, Tanaka T, Matsumura H (2012) Effect of Thiamine Repletion on Cardiac Fibrosis and Protein O-Glycosylation in Diabetic Cardiomyopathy. Diabetes Metab S7:001. doi:10.4172/2155-6156.S7-001

Copyright: ( $) 2012$ Kohda Y, et al. This is an open-access article distributed unde the terms of the Creative Commons Attribution License, which permits unrestricted use, distribution, and reproduction in any medium, provided the original author and source are credited. 
pathway as the main pathway of glucose metabolism. Instead, glucose enters the minor pathways of glucose metabolism, such as the hexosamine biosynthetic, diacylglycerol, advanced glycation end product and sorbitol pathways [24]. It is thought that cell function disorder is caused by various metabolic products based on an increase in the activity of these minor pathways [25].

Macrovascular and microvascular are general terms that refer to damaged larger (macrovascular) or smaller (microvascular) blood vessels. This damage results from a build-up of fat, blood clots and oxidation in the endothelium. Macrovascular disease is the most common cause of death among individuals with type 1 or type 2 diabetes. Macrovascular diseases include coronary artery disease, cerebrovascular disease and peripheral vascular disease. Some complications of macrovascular diseases are ischemic heart disease, heart attack (myocardial infarction), intermittent claudication, lower extremity ulcer and stroke. Complications of microvascular diseases are diabetic nephropathy, diabetic neuropathy and diabetic retinopathy. An increased plasma level of soluble vascular adhesion molecule (sVCAM)-1 acts as a marker of endothelial dysfunction and increased risk of atherosclerosis [26,27]. In diabetic patients with normal renal function, sVCAM-1 level was increased and linked to microvascular and macrovascular complications [28-31]. Thornalley et al. suggested that a decreased availability of thiamine in vascular cells in diabetes exacerbates metabolic dysfunction in hyperglycemia [15]. It has also been suggested that low plasma thiamine concentration may be a confounding factor linked to increased SVCAM-1 in diabetes [15]. In addition, thiamine deficiency in clinical diabetes may increase the fragility of vascular cells to the adverse effects of hyperglycemia and thereby, increase the risk of developing microvascular complications. Microvascular diseases damage the small blood vessels and can occur in long-term diabetic patients. Thornalley et al. suggested that correction of the low plasma thiamine concentration with thiamine supplements may decrease the risk of microvascular complications in diabetes [15]. As reported in diabetic nephropathy and retinopathy, to prevent pathogenesis and development of diabetic complications, the physiological concentration of thiamine must be sufficient to produce the desirable pharmacological effects $[18,25]$. It has previously been reported that high-dose thiamine supplementation counters diabetic dyslipidemia [32]. It has also been demonstrated that highdose application of benfotiamine as a derivative of thiamine inhibits increases in the hexosamine biosynthetic, diacylglycerol and advanced glycation end product pathways under the hyperglycemic state; prevents the pathogenesis of diabetic nephropathy and retinopathy; and delays the development of complications [25]. In streptozotocininduced diabetes, protein kinase $\mathrm{C}$ activation related to increased renal fibrosis is inhibited by the administration of thiamine and a-lipoic acid as another coenzyme of PDH that attenuates renal fibrosis in streptozotocin diabetes $[18,33,34]$.

\section{Effect of thiamine on diabetic cardiomyopathy}

Our laboratory data have clearly demonstrated the effect of thiamine repletion on cardiac fibrosis, which contributes to heart failure in streptozotocin-induced diabetic rats [35]. Diabetes was induced in rats by an intraperitoneal injection of streptozotocin, which is a chemical that is selectively toxic in the insulin-producing $\beta$-cells of mammals, to obtain an animal model of diabetes [36]. In these rats, the thiamine levels are low both in plasma as well as red blood cells and as expected, supplemental thiamine enhances these levels (Table 1). Blood glucose levels were remarkably higher in thiamine-deficient, streptozotocin-induced diabetic rats compared with normal controls.
Thiamine repletion did not influence blood glucose levels in diabetic rats that were not deficient in thiamine.

The key findings are summarized as follows:

1. Streptozotocin-induced diabetes resulted in left ventricular fractional shortening, as shown by echocardiography and this deficiency reduced the cardiac contractile activity.

2. The brain natriuretic peptide mRNA expression level in the left ventricle, a cardiac hormone that serves as a biochemical marker during heart failure, increased in streptozotocininduced diabetes.

3. Cardiac fibrosis, which is a characteristic of diabetic cardiomyopathy, was histologically shown using Sirius red stain to have a higher affinity for collagen.

4. The mRNA expression levels of thrombospondin, fibronectin, plasminogen activator inhibitor-1 and connective tissue growth factor increased, all of which promote cardiac fibrosis.

5. The $O$-glycosylated protein was higher in the left ventricle in streptozotocin-induced diabetic rats.

Thiamine repletion improved all of the above, suggesting that thiamine has the ability to protect against diabetic cardiomyopathy [35]. In support of this hypothesis, Ceylan-Isik et al. demonstrated that benfotiamine rescues cardiomyocyte contractile dysfunction [37]. Furthermore, thiamine may significantly suppress not only the cardiac fibrosis but also the $O$-glycosylated protein in the left ventricle, suggesting that activation of the hexosamine biosynthetic pathway also may be related to the pathogenesis and development of diabetic cardiomyopathy [35] (Figure 1).

\section{Protein $O$-glycosylation contributes to diabetic cardiomyopathy}

Uncontrolled elevated blood glucose levels in diabetes produce chronic tissue damage. These occur largely due to a process called

\begin{tabular}{|l|l|l|}
\hline Group & $\begin{array}{c}\text { Blood plasma thiamine } \\
(\mathrm{nM})\end{array}$ & $\begin{array}{c}\text { Red blood cells thiamine } \\
(\mathrm{nmol} / \mathrm{\mu g} \text { protein })\end{array}$ \\
\hline Control & $298.6 \pm 60.1$ & $0.98 \pm 0.07$ \\
\hline Streptozotocin diabetes & $94.1 \pm 4.51^{*}$ & $0.49 \pm 0.05^{*}$ \\
\hline $\begin{array}{l}\text { Thiamine-treated } \\
\text { streptozotocin diabetes }\end{array}$ & $409.1 \pm 17.3^{\#}$ & $0.97 \pm 0.05^{\#}$ \\
\hline Thiamine-treated & $267.8 \pm 25.9$ & $0.85 \pm 0.02$ \\
\hline
\end{tabular}

Table 1: Blood plasma and red blood cells thiamine levels in each experimental group. Each value represents the mean \pm S.E. of five experiments. ${ }^{*} p<0.01$, compared with the control. ${ }^{*} p<0.01$, compared with "Streptozotocin diabetes". Modified from Kohda et al. [35]

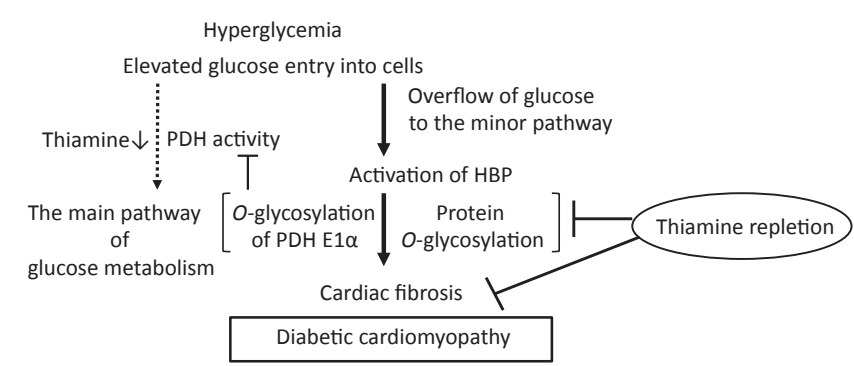

Figure 1: Hypothetical scheme to explain the prevention of diabetic cardiomyopathy by thiamine repletion [35,45,49]. HBP: Hexosamine Biosynthetic Pathway; PDH: Pyruvate Dehydrogenase. 
glycosylation, which adds a glucose molecule to protein thus modifying it and interfering with its function [38-40]. Activation of a minor pathway of glucose metabolism has been proposed as potentially contributing to the development of diabetic complications, such as the activation of the diacylglycerol, polyol or hexosamine biosynthesis pathways [24,41]. Among these, the diacylglycerol and hexosamine biosynthesis pathways most likely influence gene expression via post-translational modifications, such as phosphorylation and $O$-glycosylation of various transcriptional factors [42-44]. We have suggested that cardiac fibrosis and the level of protein $O$-glycosylation are elevated in diabetes [35]. Furthermore, we examined if the hexosamine biosynthesis pathway was involved in collagen expression in rat cardiac fibroblasts. The glucosamine treatment of rat cardiac fibroblasts caused an increase in collagen expression and enhanced $O$-glycosylated proteins [45]. These results suggest that $O$-glycosylation of protein induced by activation of the hexosamine biosynthesis pathway modifies collagen expression and contributes to diabetic cardiomyopathy [45] (Figure 1).

\section{Effect of thiamine on diabetes-induced inhibition of $\mathrm{PDH}$; the connection between PDH activity and $O$-glycosylation of PDH E1a}

The activity of $\mathrm{PDH}$ is reduced in diabetic patients, which interferes with glucose metabolism $[46,47]$. PDH activity is regulated by reversible phosphorylation. It is dependent upon PDH kinase, which phosphorylates the PDH E1 a subunit, contributing to the suppression of PDH activity [48]. It has been suggested that phosphorylation by PDH kinase renders PDH inactive.

We investigated the exact mechanism of diabetes-induced $\mathrm{PDH}$ inhibition and effect of thiamine upon rat cardiac fibroblasts. Thiamine dramatically restored high glucose-induced $\mathrm{PDH}$ inhibition. Interestingly, high glucose loads did not alter the phosphorylated PDH E1a. PDH inhibition in rat cardiac fibroblasts was not accompanied by an increase in PDH E1 $\alpha$ phosphorylation. $O$-glycosylated protein levels markedly increased in rat cardiac fibroblasts exposed to high glucose and was inhibited by thiamine. These results suggest that thiamine ameliorates diabetes-induced PDH inhibition by suppressing increased expression of the $\mathrm{O}$-glycosylated protein. $\mathrm{O}$-glycosylation of PDH E1a may be involved in the regulation of PDH activity [49] (Figure 1). Discovering the exact mechanisms that lead to a reduction in PDH activity may enable the prevention of diabetes and diabetic cardiomyopathy.

\section{Future prospects of thiamine repletion in prevention against metabolic syndrome}

Associated with excess weight, metabolic syndrome is a dangerous precursor to heart disease and type 2 diabetes. Unfortunately, obesity is occurring in endemic numbers in many countries [50]. While metabolic syndrome has its own individual characteristics, it is really a cluster of symptoms that are markers of much greater health problems to come. Once diagnosed with diabetes, many other health issues, such as nephropathy, neuropathy, macular degeneration and foot ulcers can manifest. The risk of stroke, heart disease, including heart attack, angina, atherosclerosis, arteriosclerosis and postoperative complications also increase. Metabolic syndrome inevitably leads to insulin resistance, which is a risky condition that promotes a whole cascade of other health issues apart from diabetes and heart conditions [51]. We chose Otsuka Long-Evans Tokushima Fatty (OLETF) rats, developed by Kawano et al., as models for studying human obesity $[52,53]$. Cholecystokinin is associated with satiety control mechanisms and polyphagia-induced OLETF rats lack functional cholecystokinin-A receptors [54,55]. OLETF rats exhibit progressive obesity and metabolic disorders similar to human metabolic syndrome [56]. Fourweek-old OLETF rats were randomly divided into two groups; an untreated control group and a thiamine-treated group. OLETF rats were given water or water containing $0.2 \%$ thiamine. All rats were housed in cages and provided with standard rodent chow. Body weight and food intake were measured weekly throughout the experimental period. Thiamine repletion, which plays an important role in glucose metabolism, can prevent diabetic cardiomyopathy and nephropathy, including that which occurs in obesity. We found that thiamine intervention can impact metabolic abnormalities, such as progressive obesity and metabolic disorders similar to human metabolic syndrome in polyphagia-induced OLETF rats [57]. Thiamine intervention averted obesity, mainly resulting from a reduction in visceral adiposity and prevented metabolic disorders in OLETF rats. Thiamine has the potential to prevent obesity and metabolic disorders in OLETF rats. Although corroboration is necessary, the present findings indicate that thiamine may be beneficial in targeting composite physiological abnormalities rather than individual component criteria and can be used for preventive intervention. Epidemiological data have shown that few patients develop diabetes or coronary heart disease when they consume thiamine-containing brown rice or wheat germ, as opposed to white rice [58-62]. Absorption of thiamine from food might be important in preventing metabolic syndrome. However, if thiamine intake is insufficient, it can be increased by consuming dietary supplements or medicines. Thiamine is a soluble vitamin and seems to have no potential side effects even if consumed in excess due to urinary excretion of the quantities not used by the body.

\section{Closing Notes}

Diabetes may well be the paradigm for all chronic disease. It is a syndrome that affects every organ system in the body. Metabolic syndrome should be considered as a prediabetic or a pre-cardiovascular disease state. In metabolic syndrome, there is a cluster of imbalances which work simultaneously and when this occurs, degenerative disease can accelerate at an alarming rate. Metabolic syndrome is largely a disease of modern times which can be blamed on overconsumption of carbohydrate-rich foods and excess weight. Although it is a disorder that can be easily identified and eradicated with a few dietary and lifestyle changes, many people find it difficult to make these changes. Therefore, it is critical to develop a new preventive strategy against metabolic syndrome. Obesity frequently leads to type 2 diabetes mellitus that can progress to diabetic complications. Fortunately, recent years have seen a renaissance in the development of methods to treat diabetes effectively. Current pharmaceutical interventions are moderately effective in treating clinical symptoms of metabolic syndrome; nevertheless, a basic pharmaceutical method for preventing obesity and its related metabolic disorders remains to be established. Moreover, elucidation of the mechanisms concerning obesity and diabetes mellitus contributes to the prevention of metabolic syndrome and the appearance of effective new medications available to treat diabetic cardiomyopathy.

\section{Acknowledgments}

This article was supported by a "High Technology Research Center" Project for Private Universities: matching fund subsidy from the Ministry of Education, Culture, Sports, Science and Technology of Japan.

\section{References}

1. Barr EL, Zimmet PZ, Welborn TA, Jolley D, Magliano DJ, et al. (2007) Risk of cardiovascular and all-cause mortality in individuals with diabetes mellitus, 
impaired fasting glucose, and impaired glucose tolerance: the Australian Diabetes, Obesity, and Lifestyle Study (AusDiab). Circulation 116: 151-157.

2. Bertoni AG, Tsai A, Kasper EK, Brancati FL (2003) Diabetes and idiopathic cardiomyopathy: a nationwide case-control study. Diabetes Care 26: 2791 2795.

3. Ho KKL, Pinsky JL, Kannel WB, Levy D (1993) Epidemiology of heart failure: The Framingham Study. J Am Coll Cardiol 22: 6A-13A

4. Piccini JP, Klein L, Gheorghiade M, Bonow RO (2004) New insights into diastolic heart failure: role of diabetes mellitus. Am J Med 116: 64S-75S.

5. Shindler DM, Kostis JB, Yusuf S, Quinones MA, Pitt B, et al. (1996) Diabetes mellitus, a predictor of morbidity and mortality in the Studies of Left Ventricular Dysfunction (SOLVD) Trials and Registry. Am J Cardiol 77: 1017-1020.

6. Weber MA, Bakris GL, Jamerson K, Weir M, Kjeldsen SE, et al. (2010) Cardiovascular events during differing hypertension therapies in patients with diabetes. J Am Coll Cardiol 56: 77-85

7. William BK, Marthana H, William PC (1974) Role of diabetes in congestive heart failure: The Framingham Study. Am J Cardiol 34: 29-34.

8. Rubler S, Dlugash J, Yuceoglu YZ, Kumral T, Branwood AW, et al. (1972) New type of cardiomyopathy associated with diabetic glomerulosclerosis. Am J Cardiol 30: 595-602.

9. Baliga V, Sapsford R (2009) Diabetes mellitus and heart failure - an overview of epidemiology and management. Diab Vasc Dis Res 6: 164-171.

10. Alzahrani AS, Baitei E, Zou M, Shi Y (2006) Thiamine transporter mutation: an example of monogenic diabetes mellitus. Eur J Endocrinol 155: 787-792.

11. Elbein SC, Hoffman MD, Teng K, Leppert MF, Hasstedt SJ (1999) A genomewide search for type 2 diabetes susceptibility genes in Utah Caucasians. Diabetes 48: 1175-1182.

12. Hanson RL, Ehm MG, Pettitt DJ, Prochazka M, Thompson DB, et al. (1998) An autosomal genomic scan for loci linked to type II diabetes mellitus and bodymass index in Pima Indians. Am J Hum Genet 63: 1130-1138.

13. Singleton CK, Martin PR (2001) Molecular mechanisms of thiamine utilization. Curr Mol Med 1: 197-207.

14. Jermendy G (2006) Evaluating thiamine deficiency in patients with diabetes Diab Vasc Dis Res 3: 120-121.

15. Thornalley PJ, Babaei-Jadidi R, Ali HAl, Rabbani N, Antonysunil A, et al. (2007) High prevalence of low plasma thiamine concentration in diabetes linked to a marker of vascular disease. Diabetologia 50: 2164-2170.

16. Ashokkumar B, Vaziri ND, Said HM (2006) Thiamin uptake by the humanderived renal epithelial (HEK-293) cells: cellular and molecular mechanisms. Am J Physiol Renal Physiol 291: F796-F805.

17. Laforenza U, Patrini C, Alvisi C, Faelli A, Licandro A, et al. (1997) Thiamine uptake in human intestinal biopsy specimens, including observations from a patient with acute thiamine deficiency. Am J Clin Nutr 66: 320-326.

18. Babaei-Jadidi R, Karachalias N, Ahmed N, Battah S, Thornalley PJ (2003) Prevention of incipient diabetic nephropathy by high-dose thiamine and benfotiamine. Diabetes 52: 2110-2120.

19. Gorson KC, Ropper AH (2006) Additional causes for distal sensory polyneuropathy in diabetic patients. J Neurol Neurosurg Psychiatry 77: $354-$

20. Naggar H, Ola MS, Moore P, Huang W, Bridges CC, et al. (2002) Downregulation of reduced-folate transporter by glucose in cultured RPE cells and in RPE of diabetic mice. Invest Ophthalmol Vis Sci 43: 556-563.

21. Yui $Y$, Itokawa $Y$, Kawai C (1980) Furosemide induced thiamine deficiency. Cardiovasc Res 14: 537-540.

22. Seligmann H, Halkin H, Rauchfleisch S, Kaufmann N, Motro M, et al. (1991) Thiamine deficiency in patients with congestive heart failure receiving longterm furosemide therapy: a pilot study. Am J Med 91: 151-155.

23. Babaei-Jadidi R, Karachalias N, Kupich C, Ahmed N, Thornalley PJ (2004) High-dose thiamine therapy counters dyslipidaemia in streptozotocin-induced diabetic rats. Diabetologia. 47: 2235-2246.

24. Beltramo E, Berrone E, Tarallo S, Porta M (2008) Effects of thiamine and benfotiamine on intracellular glucose metabolism and relevance in the prevention of diabetic complications. Acta Diabetol 45: 131-141.
25. Hammes HP, Du X, Edelstein D, Taguchi T, Matsumura T, et al. (2003) Benfotiamine blocks three major pathways of hyperglycemic damage and prevents experimental diabetic retinopathy. Nat Med 9: 294-299.

26. Stehouwer CDA, Gall MA, Twisk JWR, Knudsen E, Emeis JJ, et al. (2002) Increased urinary albumin excretion, endothelial dysfunction, and chronic lowgrade inflammation in type 2 diabetes. Diabetes 51: 1157-1165.

27. Jager A, van Hinsbergh VW, Kostense PJ, Emeis JJ, Nijpels G, et al. (2000) Increased levels of soluble vascular cell adhesion molecule 1 are associated with risk of cardiovascular mortality in type 2 diabetes: the Hoorn study. Diabetes 49: 485-491.

28. Lim SC, Caballero AE, Smakowski P, LoGerfo FW, Horton ES, et al. (1999) Soluble intercellular adhesion molecule, vascular cell adhesion molecule, and impaired microvascular reactivity are early markers of vasculopathy in type 2 diabetic individuals without microalbuminuria. Diabetes Care 22: 1865-1870.

29. Fasching P, Veitl M, Rohac M, Streli C, Schneider B, et al. (1996) Elevated concentrations of circulating adhesion molecules and their association with microvascular complications in insulin-dependent diabetes mellitus. J Clin Endocrinol Metab 81: 4313-4317.

30. Koga M, Otsuki M, Kubo M, Hashimoto J, Kasayama S (1998) Relationship between circulating vascular cell adhesion molecule-1 and microvascular complications in type 2 diabetes mellitus. Diabet Med 15: 661-667.

31. Soedamah-Muthu SS, Chaturvedi N, Schalkwijk CG, Stehouwer CDA Ebeling $\mathrm{P}$, et al. (2006) Soluble vascular cell adhesion molecule-1 and soluble E-selectin are associated with micro- and macrovascular complications in type 1 diabetic patients. J Diabetes Complications 20: 188-195.

32. Karachalias N, Babaei-Jadidi R, Kupich C, Ahmed N, Thornalley PJ (2005) High-dose thiamine therapy counters dyslipidemia and advanced glycation of plasma protein in streptozotocin-induced diabetic rats. Ann N Y Acad Sci 1043 : 777-783

33. Koya D, Jirousek MR, Lin YW, Ishii H, Kuboki K, et al. (1997) Characterization of protein kinase $C$ isoform activation on the gene expression of transforming growth factor- $\beta$, extracellular matrix components, and prostanoids in the glomeruli of diabetic rats. J Clin Invest 100: 115-126.

34. Melhem MF, Craven PA, Derubertis FR (2001) Effects of dietary supplementation of alpha-lipoic acid on early glomerular injury in diabetes mellitus. J Am Soc Nephrol 12: 124-133.

35. Kohda Y, Shirakawa H, Yamane K, Otsuka K, Kono T, et al. (2008) Prevention of incipient diabetic cardiomyopathy by high-dose thiamine. J Toxicol Sci 33 459-472.

36. Lenzen S (2008) The mechanisms of alloxan- and streptozotocin-induced diabetes. Diabetologia 51: 216-226.

37. Ceylan-Isik AF, Wu S, Li Q, Li SY, Ren J (2006) High-dose benfotiamine rescues cardiomyocyte contractile dysfunction in streptozotocin-induced diabetes mellitus. J Appl Physiol 100: 150-156

38. Ngoh GA, Facundo HT, Zafir A, Jones SP (2010) O-GIcNAc signaling in the cardiovascular system. Circ Res 107: 171-185

39. Lima VV, Rigsby CS, Hardy DM, Webb RC, Tostes RC (2009) O-GlcNAcylation: a novel post-translational mechanism to alter vascular cellular signaling in health and disease: focus on hypertension. J Am Soc Hypertens 3: 374-387.

40. Kudlow JE (2006) Post-translational modification by O-GIcNAc: another way to change protein function. J Cell Biochem 98: 1062-1075.

41. Hawkins M, Barzilai N, Liu R, Hu M, Chen W, et al. (1997) Role of the glucosamine pathway in fat-induced insulin resistance. J Clin Invest 99: 21732182.

42. Comer FJ, Hart GW (1999) O-GIcNAc and the control of gene expression Biochim Biophys Acta 1473:161-171.

43. Hanover JA (2001) Glycan-dependent signaling: O-linked N-acetylglucosamine FASEB J 15: 1865-1876.

44. Du XL, Edelstein D, Rossetti L, Fantus IG, Goldberg H, et al. (2000) Hyperglycemia-induced mitochondrial superoxide overproduction activates the hexosamine pathway and induces plasminogen activator inhibitor-1 expression by increasing Sp1 glycosylation. Proc Natl Acad Sci 97: 12222-12226.

45. Kohda Y, Kanematsu M, Kono T, Terasaki F, Tanaka T (2009) Protein O-glycosylation induces collagen expression and contributes to diabetic cardiomyopathy in rat cardiac fibroblasts. J Pharmacol Sci 111: 446-450. 
Citation: Kohda Y, Tanaka T, Matsumura H (2012) Effect of Thiamine Repletion on Cardiac Fibrosis and Protein O-Glycosylation in Diabetic Cardiomyopathy. J Diabetes Metab S7:001. doi:10.4172/2155-6156.S7-001

Page 5 of 5

46. Brownlee M (2005) The pathobiology of diabetic complications: a unifying mechanism. Diabetes 54: 1615-1625.

47. Bajotto G, Murakami T, Nagasaki M, Tamura T, Tamura N, et al. (2004) Downregulation of the skeletal muscle pyruvate dehydrogenase complex in the Otsuka Long-Evans Tokushima Fatty rat both before and after the onset of diabetes mellitus. Life Sci 75: 2117-2130.

48. Pilegaard H, Neufer PD (2004) Transcriptional regulation of pyruvate dehydrogenase kinase 4 in skeletal muscle during and after exercise. Proc Nutr Soc 63: 221-226.

49. Kohda Y, Umeki M, Kono T, Terasaki F, Matsumura H, et al. (2010) Thiamine ameliorates diabetes-induced inhibition of pyruvate dehydrogenase $(\mathrm{PDH})$ in rat heart mitochondria: investigating the discrepancy between PDH activity and PDH E1 $\alpha$ phosphorylation in cardiac fibroblasts exposed to high glucose. $J$ Pharmacol Sci 113: 343-352.

50. WHO (2000) Obesity: preventing and managing the global epidemic. Report of a WHO consultation. World Health Organ Tech Rep Ser 894: 1-253.

51. Liu A, Abbasi F, Reaven GM (2011) Adiposity indices in the prediction of metabolic abnormalities associated with cardiovascular disease in non-diabetic adults. Nutr Metab Cardiovasc Dis 21: 553-560.

52. Kawano K, Hirashima T, Mori S, Saitoh Y, Kurosumi M, et al. (1991) New inbred strain of Long-Evans Tokushima lean rats with IDDM without lymphopenia. Diabetes 40: 1375-1381.

53. Kawano K, Hirashima T, Mori S, Saitoh Y, Kurosumi M, et al. (1992) Spontaneous long-term hyperglycemic rat with diabetic complications. Otsuka Long-Evans Tokushima Fatty (OLETF) strain. Diabetes 41: 1422-1428.

54. Takiguchi S, Takata Y, Funakoshi A, Miyasaka K, Kataoka K, et al. (1997) Disrupted cholecystokinin type-A receptor (CCKAR) gene in OLETF rats. Gene 197: 169-175.
55. Takiguchi S, Takata Y, Takahashi N, Kataoka K, Hirashima T, et al. (1998) A disrupted cholecystokinin A receptor gene induces diabetes in obese rats synergistically with ODB1 gene. Am J Physiol 274: E265-270.

56. Schroeder M, Zagoory-Sharon O, Shbiro L, Marco A, Hyun J, et al. (2009) Development of obesity in the Otsuka Long-Evans Tokushima Fatty rat. Am J Physiol Regul Integr Comp Physiol 297: R1749-1760.

57. Tanaka T, Kono T, Terasaki F, Yasui K, Soyama A, et al. (2010) Thiamine prevents obesity and obesity-associated metabolic disorders in OLETF rats. J Nutr Sci Vitaminol 56: 335-346.

58. McKeown NM, Meigs JB, Liu S, Wilson PW, Jacques PF (2002) Whole-grain intake is favorably associated with metabolic risk factors for type 2 diabetes and cardiovascular disease in the Framingham Offspring Study. Am J Clin Nutr 76: 390-398.

59. Keast DR, Rosen RA, Arndt EA, Marquart LF (2011) Dietary modeling shows that substitution of whole-grain for refined-grain ingredients of foods commonly consumed by US children and teens can increase intake of whole grains. J Am Diet Assoc 111: 1322-1328.

60. Zhang G, Pan A, Zong G, Yu Z, Wu H, et al. (2011) Substituting white rice with brown rice for 16 weeks does not substantially affect metabolic risk factors in middle-aged Chinese men and women with diabetes or a high risk for diabetes. J Nutr 141: 1685-1690.

61. Zhang G, Malik VS, Pan A, Kumar S, Holmes MD, et al. (2010) Substituting brown rice for white rice to lower diabetes risk: a focus-group study in Chinese adults. J Am Diet Assoc 110: 1216-1221.

62. Harris KA, Kris-Etherton PM (2010) Effects of whole grains on coronary heart disease risk. Curr Atheroscler Rep 12: 368-376.
This article was originally published in a special issue, Diabetic Cardiomyopathy handled by Editor(s). Dr. Sophie Van Linthout, University Medicin Berlin, Germany 